\title{
Decision Support Systems for Land Suitability Evaluation on Rice Cultivation using ELECTRE Method
}

\author{
Ircham $\mathrm{Ali}^{1 *}$, Vincensius Gunawan ${ }^{2}$, Kusworo $\mathrm{Adi}^{3}$ \\ ${ }^{1}$ Master of Information Systems, School of Postgraduate study, Diponegoro University, Indonesia \\ ${ }^{2}$ Departement of Physics, Faculty of Science and Mathematics, Diponegoro University, Indonesia \\ ${ }^{3}$ Departement of Physics, Faculty of Science and Mathematics, Diponegoro University, Indonesia
}

\begin{abstract}
Land suitability evaluation has an important role in determining the environmental boundaries of sustainable land resource management. The purpose of this study is to evaluate the suitability of land use in rice cultivation in Magelang, Indonesia. Environmental factors such as rainfall, drainage, depth, $\mathrm{pH}$, organic matter content, slopes, and erosion level are used as criteria compared to 5 alternative lands (Sawangan, Mangunsari, Tirtosari, Podosoko, and Kapuhan). The ELECTRE method as one of the multi-criteria decision-making methods chosen to solve the concept ambiguity problem in land suitability assessment. The result shows that the application of this method is quite effective for decision making so that alternatives are obtained that have the highest land use suitability compared to other alternatives for environmentally friendly rice cultivation. Finally, a decision support system with a web-based ELECTRE Method is presented to facilitate decision-makers in obtaining more accurate land suitability information.
\end{abstract}

Keywords. Land suitability evaluation, sustainable land resources, ELECTRE method, and decision-making.

\section{Introduction}

Sustainable land resources are an important part of realizing sustainable agriculture. At present sustainable agriculture has urgency in improving land quality and the potential to increase food supply [1]. Agriculture, especially rice cultivation is a major producer of staples, while land degradation poses a threat to environmental sustainability. Land use decisions for rice cultivation can be started from the proper planning, management, and use of land-based on land suitability factors. Evaluation of land suitability as a recommended land assessment is to find out the suitability level [2].

Land suitability evaluation as an approach to land valuation based on environmental factors on predetermined land [3]. To determine the suitability of land in rice cultivation, we

* Corresponding author: id.irchamali@gmail.com 
need a reliable decision support system to evaluate the suitability of land use. Several decision-making methods have been used for land suitability. One of them is MCDM (Multicriteria decision making), MCDM is divided into two namely MADM (Multi-attribute decision making) and MODM (Multi-object decision making). MADM technique in this case is chosen because it has advantages compared to MODM in ranking and pairwise comparisons [4].

Several evaluations have been carried out for land suitability using one of the methods from MADM such as the application of the PROMETHEE method for selecting solar power plant locations [5], the TOPSIS method is used in the suitability of site selection at hydrogensulfide (H2S) energy plants [6], and evaluation of airport establishment based on environmental factors using VIKOR [7]. However, the three methods could not be stand alone in weighting and capture a large number of land suitability criteria. This is quite answered with the application of the ELECTRE method in the evaluation of land-use suitability [8].

The ELECTRE method is a multi-criteria decision making analysis method with the concept of outranking using pairwise comparison of alternatives based on each appropriate criterion [9]. The advantage of this method is that it can be applied with alternative conditions more than the number of criteria, so the concept of outranking relations can identify between two alternatives. The superiority of the ELECTRE method in the selection and elimination procedure based on alternative options is very precisely applied to the land suitability evaluation process [10].

There are several previous studies that use ELECTRE methods such as land suitability evaluation in wheat cultivation [11], evaluation of solar panel installation locations [12], identification of wind turbine installation locations [13], selection of the best alternatives for water resource allocation planning [14], decision making analysis for renewable energy selection [15], the ELECTRE method is applied to calculate the strength of outranking relationships of various power plants [16], and analysis of land-use suitability for rural tourism [8].

Based on the superiority of the method and problem-solving in previous studies, this study applies the ELECTRE method to evaluate the suitability of land use in rice cultivation. This research is to build a decision support system that helps the process of ranking the best land for rice cultivation based on the results of the evaluation of the suitability of land use. Evaluation of land-use suitability by applying the ELECTRE method will be based on environmental factors such as water availability, root media, nutrient retention, and erosion hazards. Criteria that is used in this study are the number of wet months, drainage, soil depth, average $\mathrm{pH}$, c-organic, slope, and erosion level.

\section{Theoretical Review}

This session will explain the decision support system, land suitability evaluation, and the ELECTRE Method. This session will also explain how to use the methodology used in this study.

\subsection{Decision Support Systems}

Decision Support Systems (DSS) is a system that has ability to solve semi-structured and unstructured problems. DSS is also defined as computer-based information systems at the management level used in the decision-making process [17]. The most popular and widely used DSS method is Multi-criteria decision making (MCDM). MCDM has advantage of making decisions and producing ratings at each level of criteria and alternatives [18]. MCDM 
technique with the ELECTRE Method is used as a web-based decision support system for evaluating land suitability in rice cultivation. The initial decision-making concept in MCDM is illustrated in a comparison matrix between alternatives and the criteria as shown in Fig. 1.

Table 1. Pairwise comparison matrix (x).

\begin{tabular}{c|cccc}
\hline \multirow{2}{*}{ Alternative } & \multicolumn{4}{|c}{ Criteria } \\
\cline { 2 - 5 } A1 & C1 & C2 & $\cdots$ & Cn \\
\cline { 2 - 5 } A2 & $X_{11}$ & $X_{12}$ & $\cdots$ & $X_{1 \mathrm{n}}$ \\
$\vdots$ & $X_{21}$ & $X 23$ & $\cdots$ & $X_{2 n}$ \\
Am & $\vdots$ & $\vdots$ & $\vdots$ & $\vdots$ \\
& $X_{\mathrm{ml}}$ & $X_{\mathrm{m} 2}$ & $\cdots$ & $X_{\mathrm{m}}$
\end{tabular}

\subsection{Land Suitability Evaluation}

Based on [3] land evaluation, it is defined as the process of assessing land resources using proven methods for specific purposes. So, in this study land suitability evaluation can be interpreted as a process of land appraisal based on criteria and land quality using the ELECTRE method to determine the level of land suitability for its use. The object of research or land use in question is rice fields with an irrigation system with rice cultivation. The criteria is used for evaluating land suitability consist of 7 criteria taken from the land suitability assessment guidelines [19].

Table 2. Land suitability criteria for rice cultivation.

\begin{tabular}{|c|c|c|c|c|}
\hline \multirow{2}{*}{ Criteria } & \multicolumn{4}{|c|}{ Class of Suitable land } \\
\cline { 2 - 5 } & $\mathbf{S 1}$ & $\mathbf{S 2}$ & $\mathbf{S 3}$ & $\mathbf{N}$ \\
\hline $\begin{array}{c}\text { Rainfall } \\
(>200 \mathrm{~mm})\end{array}$ & $6-8$ & $4-<6$ & $\begin{array}{c}2-<4 \\
>8-10\end{array}$ & $\begin{array}{c}<2 \\
>10\end{array}$ \\
\hline Drainage & $\begin{array}{c}\text { inhibited, } \\
\text { rather } \\
\text { inhibited }\end{array}$ & rather good & $\begin{array}{c}\text { very inhibited, } \\
\text { good, rather } \\
\text { quick }\end{array}$ & quick \\
\hline Soil Depth (cm) & $>50$ & $40-50$ & $25-40$ & $<25$ \\
\hline pH average & $5,5-7,0$ & $\begin{array}{c}4,5-5,5 \\
7,0-8,0\end{array}$ & $\begin{array}{c}<4,5 \\
>0,8\end{array}$ & - \\
\hline C-organic (\%) & $>1,2$ & $0,8-1,2$ & $<0,8$ & - \\
\hline Slope (\%) & $<3$ & $3-5$ & $5-8$ & $>8$ \\
\hline Erosion level & - & very mild & mild & $\begin{array}{c}\text { moderate - } \\
\text { danger }\end{array}$ \\
\hline
\end{tabular}

Seven criteria (Table 2) are codified into C1-C7 and the alternative used is in the form of agricultural fields for rice cultivation with a total of 5 alternatives consisting of Sawangan, Mangunsari, Tirtosari, Podosoko, and Kapuhan which are then codified into A1-A8. Based 
on guidance on land suitability [2,3], the land classes are divided into 2 classes, namely the order S (suitable) and $\mathrm{N}$ (not suitable). Therefore, when an alternative has a criterion value in class $\mathrm{N}$ means it has a low match value, and vice versa when it has Class $\mathrm{S}$.

\subsection{ELECTRE method}

Elimination Et choix tradusiant la realite (ELECTRE) method is one of the outranking methods for multi-criteria decision making. This method involves a systematic analysis between pairs of different alternatives from a set of evaluation criteria. Evaluations conducted that use the ELECTRE method will produce the best alternative ranking relationship with the assumption that alternative one can dominate to the other alternatives [9]. Likewise, when the alternatives are equally good, weights are needed for all criteria as a comparison to assess [20]. The steps of the ELECTRE method applied in evaluating land suitability are as follows:

\subsubsection{Normalization of the decision matrix ( $r$ )}

The ELECTRE method starts by forming a pairwise comparison of each alternative in each criterion $\left(x_{i j}\right)$ as in Table 1 . The value of $\mathrm{x}$ is obtained from a rating of values on a scale of 14 adjusted to the rules of the land evaluation framework (Table 2). Reference land suitability class S (Suitable: $\mathrm{S} 1, \mathrm{~S} 2, \mathrm{~S} 3$ ) and $\mathrm{N}$ (Not suitable), so $\mathrm{S} 1=4, \mathrm{~S} 2=3, \mathrm{~S} 3=2$, and $\mathrm{N}=1$. Then the value of $\mathrm{x}$ must be normalized into a comparable scale $\left(r_{i}\right)$ :

$$
r_{i j}=\frac{x_{i j}}{\sqrt{\sum_{i=1}^{m} x_{i j}^{2}}}
$$

where $i=1,2, \ldots, m$ and $j=1,2, \ldots, n$ in this case $m$ is the number of alternatives and $n$ is the number of criteria.

\subsubsection{Defining the preference table (v)}

At this stage, the decision-maker must give preference weight (w) to each criterion that expresses the reality $\left(w_{i}\right)$.

$$
W=\left(w_{1}, w_{1}, \ldots, w_{n}\right)
$$

with the determination of weights using the choice of scale 1-5. So that the total number of $\mathrm{w}$ is equal to 1 if the criterion is 1 , or according to the equation

$$
\sum_{j=1} w=1
$$

The weight $(w)$ is then multiplied by the pairwise comparison matrix $(x)$ to form the reference matrix $(v)$ :

$$
v_{i j}=w_{j} \cdot x_{i j}
$$

\subsubsection{Determine the Concordance dan Discordance Index}

The formation of concordance index and discordance index are done through an assessment of the ranking relations between alternatives. For each alternative pair $A_{k}$ and $A_{i}$ with assumptions $(k, l=1,2,3, \ldots, m$ and $k \neq 1)$, the set of criteria $j$ is divided into two namely concordance and discordance. When a criterion in an alternative is included concordance

$$
C_{k l}=\left\{j, v_{k j} \geq v_{i j}\right\}, \text { for } j=1,2,3, \ldots n
$$

Whereas discordance is complementary from the set with the equation

$$
D_{k l}=\left\{j, v_{k j}<v_{i j}\right\}, \text { for } \mathrm{j}=1,2,3, \ldots \mathrm{n}
$$




\subsubsection{Calculating the Concordance and Discordance matrix}

Determination of the value in the concordance matrix (C) is obtained by adding up the weights included in the concordance subset:

$$
C_{k l}=\sum_{j \in C_{k l}} W_{j}
$$

So the resulting concordance matrix is

$$
C=\left[\begin{array}{ccccc}
- & c_{12} & c_{13} & \ldots & c_{1 n} \\
c_{21} & - & c_{23} & \ldots & c_{2 n} \\
\vdots & & & & \\
c_{m 1} & c_{m 2} & c_{m 3} & \ldots & -
\end{array}\right]
$$

Meanwhile, to calculate the discordance matrix by dividing the maximum difference between the criteria included in the set of discordance parts by the maximum difference in the value of all available:

So the resulting discordance matrix is

$$
D_{k l}=\frac{\max \left\{\left|v_{k j}-v_{i j}\right|\right\} j \in D_{k}}{\max \left\{\left|v_{k j}-v_{i j}\right|\right\} \forall j}
$$

$$
D=\left[\begin{array}{ccccc}
- & d_{12} & d_{13} & \ldots & d_{1 n} \\
d_{21} & - & d_{23} & \ldots & d_{2 n} \\
\vdots & & & & - \\
d_{m 1} & d_{m 2} & d_{m 3} & \ldots & -
\end{array}\right]
$$

\subsubsection{Determine the Concordance and Discordance dominant matrix}

The concordance dominant matrix $(f)$ can be formed by the help of a threshold value on the concordance matrix. Matrix $\mathrm{f}$ is obtained by comparing each element value of the concordance matrix with the threshold value. Threshold is obtained by equation

$$
\underline{c}=\frac{\sum_{k=1}^{n} \Sigma^{n l=1} c_{k l}}{\mathrm{~m} *(\mathrm{~m}-1)}
$$

Alternative $A_{k}$ can have the opportunity to dominate $A_{i}$, if the concordance index $C_{k}$ exceeds the threshold $\underline{c}$ :

$$
f_{k l}=1, \text { jika } c_{k l} \geq c \text { dan } f_{k l}=0 \text {,jika } c_{k l}<\underline{c}
$$

The dominant discordance matrix (d) can also be formed by the help of a threshold (d) for the equation:

$$
\underline{d}=\frac{\sum_{k=1}^{n} \Sigma^{n l=1} d_{k l}}{\mathrm{~m} *(\mathrm{~m}-1)}
$$

Alternative $A_{k}$ can have the opportunity to dominate $A$, if the concordance index $C_{\iota}$ exceeds the threshold $\underline{c}$ :

$$
g_{k l}=1, \text { jika } d_{k l} \geq d \text { dan } g_{k l}=0, j i k a d_{k l}<\underline{d}_{(4)}
$$

\subsubsection{Determine the aggregate dominance}

The aggregate dominance matrix $(e)$ is the multiplication of the matrix element $f$ with the matrix element $g$, by the equation:

$$
e_{k l}=f_{k l} \times g_{k l}
$$




\subsubsection{Elimination of less favorable alternatives}

Matrix $e$ shows the order of alternatives that meet the criteria that are if $e_{k l}=1$ then it indicates that the alternative $A_{k}$ is preferred over $A$. So that the rows in matrix $e$ that have the least number of $e_{k l}=1$ can be eliminated. Thus, the best alternative is an alternative that is able to dominate other alternatives.

\section{Implementation}

Implementation of the ELECTRE Method is used as decision support systems uses land characteristics data, soil lab test data, and respondent data from agricultural experts in Magelang Regency. Giving a rating value of compatibility between alternatives and criteria based on guidelines (Table 2 ) with the provisions $\mathrm{S} 1=4, \mathrm{~S} 2=3, \mathrm{~S} 3=2$ and $\mathrm{N}=1$. While, giving preference weights $(w)$ criteria is done by experts based on the Likert scale 1-5. The results of the weighting criteria as in Table 3 and pairwise comparisons $(x)$ as a reference for calculations use the ELECTRE method in Table 4.

Table 3. List of Criteria Weight.

\begin{tabular}{|c|c|c|c|}
\hline Code & Criterias & $\begin{array}{c}\text { Level of } \\
\text { Importance }\end{array}$ & Value \\
\hline C1 & Rainfall & Not too Important & 2 \\
\hline C2 & Drainage & Important & 4 \\
\hline C3 & Soil Depth & Quite Important & 3 \\
\hline C4 & pH Average & Very Important & 5 \\
\hline C5 & C-organic & Very Important & 5 \\
\hline C6 & Slope & Quite Important & 3 \\
\hline C7 & Erosion Level & Important & 4 \\
\hline
\end{tabular}

Table 4. Pairwise comparison table (x).

\begin{tabular}{|c|c|c|c|c|c|c|c|}
\hline Code & C1 & C2 & C3 & C4 & C5 & C6 & C7 \\
\hline A1 & 3 & 3 & 2 & 4 & 4 & 4 & 4 \\
\hline $\mathbf{A 2}$ & 3 & 4 & 2 & 4 & 4 & 4 & 3 \\
\hline $\mathbf{A 3}$ & 3 & 3 & 3 & 4 & 4 & 4 & 3 \\
\hline $\mathbf{A 4}$ & 3 & 4 & 2 & 4 & 4 & 4 & 2 \\
\hline $\mathbf{A 5}$ & 3 & 2 & 3 & 4 & 4 & 3 & 2 \\
\hline
\end{tabular}

The data analysis process in this study uses an Information System Framework which is divided into three stages, namely input, process, and output. First, the input stage is the process of analysis data in the form of 7 criteria and 5 alternatives. Criteria are the land using requirements or environmental characteristics that are used as a reference for determining values and decision making. First, Alternatives are strategic choices of locations or research 
areas that are being evaluated for land suitability for rice cultivation. Second, the stage of the process for conducting analysis using the ELECTRE method with 7 steps. Third, the output is the results obtained in the form of the best ranking of the results of the alternatives between one another. Information from data management to the results obtained is presented in an application in the form of a DSS website. Each stage is interconnected in accordance with the flow of information system development, in full in Figure 1.

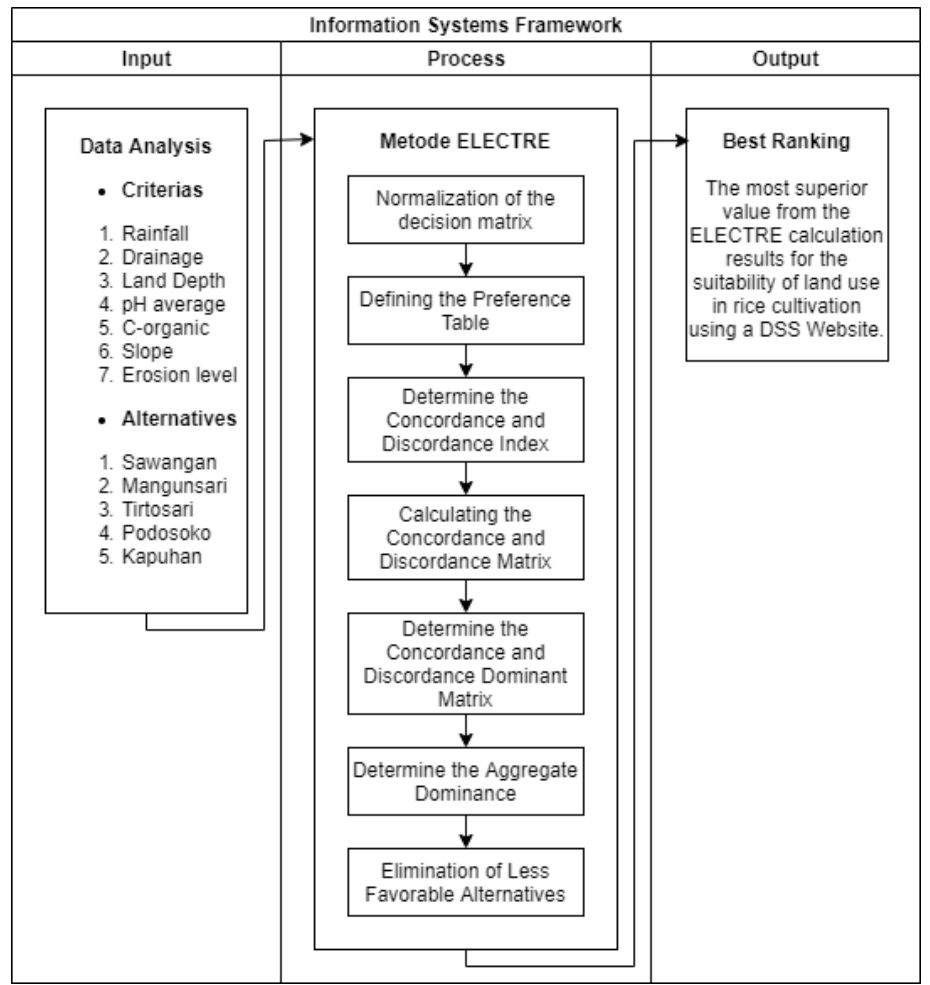

Fig. 1. Information Systems Framework for DSS

\section{Result and Discussions}

Based on the value of alternative pairwise comparisons with the criteria $(x)$ that have been obtained (Table 4), the first stage of land suitability evaluation using the Electron Method is the process of normalizing the decision matrix $(r)$ with the results (Table 5).

Table 5. Normalization of the decision matrix.

\begin{tabular}{|c|c|c|c|c|c|c|c|}
\hline Code & C1 & C2 & C3 & C4 & C5 & C6 & C7 \\
\hline $\mathbf{A 1}$ & 0.447214 & 0.408248 & 0.365148 & 0.447214 & 0.447214 & 0.468165 & 0.617213 \\
\hline $\mathbf{A 2}$ & 0.447214 & 0.544331 & 0.365148 & 0.447214 & 0.447214 & 0.468165 & 0.46291 \\
\hline $\mathbf{A 3}$ & 0.447214 & 0.408248 & 0.547723 & 0.447214 & 0.447214 & 0.468165 & 0.46291 \\
\hline $\mathbf{A 4}$ & 0.447214 & 0.544331 & 0.365148 & 0.447214 & 0.447214 & 0.468165 & 0.308607 \\
\hline $\mathbf{A 5}$ & 0.447214 & 0.272166 & 0.547723 & 0.447214 & 0.447214 & 0.351123 & 0.308607 \\
\hline
\end{tabular}


After getting the value of $r$ then the weighting process is carried out on the normalized matrix ( $v$ ) by multiplying $w$ by $r$, the results are as in Table 6 .

Table 6. Weighting of normalized matrix.

\begin{tabular}{|c|c|c|c|c|c|c|c|}
\hline Code & C1 & C2 & C3 & C4 & C5 & C6 & C7 \\
\hline $\mathbf{A 1}$ & 0.894428 & 1.632992 & 1.095444 & 2.23607 & 2.23607 & 1.404495 & 2.468852 \\
\hline $\mathbf{A 2}$ & 0.894428 & 2.177324 & 1.095444 & 2.23607 & 2.23607 & 1.404495 & 1.85164 \\
\hline $\mathbf{A 3}$ & 0.894428 & 1.632992 & 1.632992 & 2.23607 & 2.23607 & 1.404495 & 1.85164 \\
\hline $\mathbf{A 4}$ & 0.894428 & 2.177324 & 1.095444 & 2.23607 & 2.23607 & 1.404495 & 1.234428 \\
\hline $\mathbf{A 5}$ & 0.894428 & 1.088664 & 1.632992 & 2.23607 & 2.23607 & 1.053369 & 1.234428 \\
\hline
\end{tabular}

After obtaining the value of $v$, then determine the set of concordance and discordance indexes by following equation (5)(6), with the results:

Table 7. Determine the Concordance Index.

\begin{tabular}{|c|c|c|c|c|c|}
\hline Code & A1 & A2 & A3 & A4 & A5 \\
\hline A1 & - & $\begin{array}{c}\{1,3,4,5, \\
6,7\}\end{array}$ & $\begin{array}{c}\{1,2,4,5, \\
6,7\}\end{array}$ & $\begin{array}{c}\{1,3,4,5, \\
6,7\}\end{array}$ & $\begin{array}{c}\{1,2,4,5, \\
6,7\}\end{array}$ \\
\hline $\mathbf{A 2}$ & $\begin{array}{c}\{1,2,3,4, \\
5,6\}\end{array}$ & - & $\begin{array}{c}\{1,2,4,5, \\
6,7\}\end{array}$ & $\begin{array}{c}\{1,2,3,4, \\
5,6,7\}\end{array}$ & $\begin{array}{c}\{1,2,4,5, \\
6,7\}\end{array}$ \\
\hline $\mathbf{A 3}$ & $\begin{array}{c}\{1,2,3,4, \\
5,6\}\end{array}$ & $\begin{array}{c}\{1,3,4,5, \\
6,7\}\end{array}$ & - & $\begin{array}{c}\{1,3,4,5, \\
6,7\}\end{array}$ & $\begin{array}{c}\{1,2,3,4, \\
5,6,7\}\end{array}$ \\
\hline $\mathbf{A 4}$ & $\begin{array}{c}\{1,2,3,4, \\
5,6\}\end{array}$ & $\begin{array}{c}\{1,2,3,4, \\
5,6\}\end{array}$ & $\begin{array}{c}\{1,2,4,5, \\
6\}\end{array}$ & - & $\begin{array}{c}\{1,2,4,5, \\
6,7\}\end{array}$ \\
\hline $\mathbf{A 5}$ & $\{1,3,4,5\}$ & $\{1,3,4,5\}$ & $\{1,3,4,5\}$ & $\begin{array}{c}\{1,3,4,5, \\
7\}\end{array}$ & - \\
\hline
\end{tabular}

Table 8. Determine the Discordance Index.

\begin{tabular}{|c|c|c|c|c|c|}
\hline Code & A1 & A2 & A3 & A4 & A5 \\
\hline $\mathbf{A 1}$ & - & $\{2\}$ & $\{3\}$ & $\{2\}$ & $\{3\}$ \\
\hline $\mathbf{A 2}$ & $\{7\}$ & - & $\{3\}$ & & $\{3\}$ \\
\hline $\mathbf{A 3}$ & $\{7\}$ & $\{2\}$ & - & $\{2\}$ & \\
\hline $\mathbf{A 4}$ & $\{7\}$ & $\{7\}$ & $\{3,7\}$ & - & $\{3\}$ \\
\hline $\mathbf{A 5}$ & $\{2,6,7\}$ & $\{2,6,7\}$ & $\{2,6,7\}$ & $\{2,6\}$ & - \\
\hline
\end{tabular}

After knowing $C_{*}$ and $D_{v}$, the next step is to form a concordance and discordance matrix by following equation (7)(9) which results in Table 9 and Table 10. 
Table 9. Determine the Concordance Matrix.

\begin{tabular}{|c|c|c|c|c|c|}
\hline Code & A1 & A2 & A3 & A4 & A5 \\
\hline A1 & - & 22 & 23 & 22 & 23 \\
\hline $\mathbf{A 2}$ & 22 & - & 23 & 26 & 23 \\
\hline $\mathbf{A 3}$ & 22 & 22 & - & 22 & 26 \\
\hline $\mathbf{A 4}$ & 22 & 22 & 19 & - & 23 \\
\hline $\mathbf{A 5}$ & 15 & 15 & 15 & 19 & - \\
\hline
\end{tabular}

Table 10. Determine the Discordance Matrix.

\begin{tabular}{|c|c|c|c|c|c|}
\hline Code & A1 & A2 & A3 & A4 & A5 \\
\hline $\mathbf{A 1}$ & - & 0.88192 & 0.88742 & 0.44096 & 0.44371 \\
\hline $\mathbf{A 2}$ & 1 & - & 1 & 0 & 0.50312 \\
\hline $\mathbf{A 3}$ & 1 & 0.99381 & - & 0.88192 & 0 \\
\hline $\mathbf{A 4}$ & 1 & 1 & 1 & - & 0.50312 \\
\hline $\mathbf{A 5}$ & 1 & 1 & 1 & 1 & - \\
\hline
\end{tabular}

After obtaining the values in the concordance and discordance matrices, then the threshold concordance $\underline{c}=21$ and the threshold discordance $\underline{d}=0.777$. In accordance with equation (12)(14) a concordance dominant matrix is formed with the results:

Table 11. Determine Concordance Dominant Matrix.

\begin{tabular}{|c|c|c|c|c|c|}
\hline Code & A1 & A2 & A3 & A4 & A5 \\
\hline A1 & - & 1 & 1 & 1 & 1 \\
\hline $\mathbf{A 2}$ & 1 & - & 1 & 1 & 1 \\
\hline $\mathbf{A 3}$ & 1 & 1 & - & 1 & 1 \\
\hline $\mathbf{A 4}$ & 1 & 1 & 0 & - & 1 \\
\hline $\mathbf{A 5}$ & 0 & 0 & 0 & 0 & - \\
\hline
\end{tabular}


Table 12. Determine Discordance Dominant Matrix.

\begin{tabular}{|c|c|c|c|c|c|}
\hline Code & A1 & A2 & A3 & A4 & A5 \\
\hline A1 & - & 1 & 1 & 0 & 0 \\
\hline $\mathbf{A 2}$ & 1 & - & 1 & 0 & 0 \\
\hline $\mathbf{A 3}$ & 1 & 1 & - & 1 & 0 \\
\hline $\mathbf{A 4}$ & 1 & 1 & 1 & - & 0 \\
\hline $\mathbf{A 5}$ & 1 & 1 & 1 & 1 & - \\
\hline
\end{tabular}

Next, determine the aggregate of the dominant matrix by multiplying the $f_{k l}$ with $g_{k}$ whose results are in accordance with Table 13.

Table 13. Determine the Dominance Matrix Aggregate.

\begin{tabular}{|c|c|c|c|c|c|}
\hline Code & A1 & A2 & A3 & A4 & A5 \\
\hline $\mathbf{A 1}$ & - & 1 & 1 & 0 & 0 \\
\hline $\mathbf{A 2}$ & 1 & - & 0 & 1 & 0 \\
\hline $\mathbf{A 3}$ & 1 & 1 & - & 1 & 0 \\
\hline $\mathbf{A 4}$ & 1 & 1 & 0 & - & 0 \\
\hline $\mathbf{A 5}$ & 0 & 0 & 0 & 0 & - \\
\hline
\end{tabular}

The final step, eliminating alternatives that are less favorable to determine the best ranking of land suitability evaluation.

\begin{tabular}{|c|c|c|c|c|c|}
\hline \multicolumn{6}{|c|}{ \#7 Elimination of less favorable alternatives } \\
\hline Rank & Code & Alternative & Value $(\mathrm{X})$ & Value (Ekl) & Status \\
\hline 1 & A3 & Tirtosari & 24 & 3 & Highly Suitable \\
\hline 2 & $\mathrm{~A} 1$ & Sawangan & 24 & 2 & Moderately Suitable \\
\hline 3 & $\mathrm{~A} 2$ & Mangunsari & 24 & 2 & Moderately Suitable \\
\hline 4 & A4 & Podosoko & 23 & 2 & Moderately Suitable \\
\hline 5 & A5 & Kapuhan & 21 & 0 & Marginally Suitable \\
\hline
\end{tabular}

Fig. 2. Elimination of less favorable alternatives. 


\section{Conclusion}

Based on the results of the analysis and discussion, it can be concluded that the criteria that can affect the evaluation of land suitability in rice cultivation consist of 7 criteria, namely rainfall, drainage, depth, $\mathrm{pH}$, c-organic, slope, and erosion rate. This decision support system uses the ELECTRE method which is quite effectively applied as an analysis tool. Ranking conducted according to the method has succeeded in eliminating several alternatives to get the best alternative. A5 is eliminated first because it does not have a value of 1 , then between the other alternatives is compared to find out the best. The same value is in alternatives A1, A2, A4, while the largest value is in A3 with a value of 3. So that the ranking order from highest to low is paddy fields in Tirtosari, Sawangan, Mangunsari, Podosoko, and Kapuhan.

Future research can try to apply the MCDM method to decision support systems combined with geographic information systems. So that attribute and spatial data can describe the analysis of an object with a more complex and real-time visualization.

\section{References}

1 FAO, Transforming Food and Agriculture to Achieve the SDGs. Rome, Italy (2018)

2 FAO, Land Evaluation towards a Revised Framework: Land and Water Discussion Paper, 6th ed. Rome, Italy (2007)

3 FAO, A Framework for Land Evaluation, FAO Soils. Rome, Italy (1976)

4 A. Mardani, A. Jusoh, and E. Kazimieras, Expert Systems with Applications Fuzzy multiple criteria decision-making techniques and applications - Two decades review from 1994 to 2014, Expert Syst. Appl., 42, 4126-4148 (2015)

5 Y. Wu, B. Zhang, C. Wu, T. Zhang, and F. Liu, Optimal site selection for parabolic trough concentrating solar power plant using extended PROMETHEE method: A case in China, Renew. Energy, 143, 1910-1927 (2019)

6 S. Seker and N. Aydin, Hydrogen production facility location selection for Black Sea using entropy based TOPSIS under IVPF environment, Int. J. Hydrogen Energy, 40, 1$14(2020)$

7 A. Kumar, A. A, and H. Gupta, Evaluating green performance of the airports using hybrid BWM and VIKOR methodology, Tour. Manag., 76, 1-16 (2020)

8 Ç. K. Ayhan, T. C. Taşh, F. Özkök, and H. Tatlı, Land use suitability analysis of rural tourism activities: Yenice, Turkey, Tour. Manag., 76, 1-11 (2020)

9 K. Govindan and M. B. Jepsen, ELECTRE: A comprehensive literature review on methodologies and applications, Eur. J. Oper. Res., 250, 1-29 (2016)

$10 \mathrm{X}$. Yu, S. Zhang, X. Liao, and X. Qi, ELECTRE methods in prioritized MCDM environment, Inf. Sci. (Ny)., 424, 301-316 (2018)

11 A. Mendas and A. Delali, Integration of MultiCriteria Decision Analysis in GIS to develop land suitability for agriculture: Application to durum wheat cultivation in the region of Mleta in Algeria, Comput. Electron. Agric., 83, 117-126 (2012)

12 J. M. Sánchez-Lozano, M. S. García-Cascales, and M. T. Lamata, Identification and selection of potential sites for onshore wind farms development in region of murcia, Spain, Energy, 73, 311-324 (2014)

13 J. M. Sánchez-Lozano, C. Henggeler, M. S. García-cascales, and L. C. Dias, GIS-based photovoltaic solar farms site selection using ELECTRE-TRI: Evaluating the case for Torre Pacheco, Murcia, Southeast of Spain, Renew. Energy, 66, 478-494 (2014) 
14 V. Kumar, L. Del Vasto-Terrientes, A. Valls, and M. Schuhmacher, Adaptation strategies for water supply management in a drought prone Mediterranean river basin: Application of outranking method, Sci. Total Environ., 540, 344-357, (2016)

15 M. Mousavi, H. Gitinavard, and S. M. Mousavi, A soft computing based-modified ELECTRE model for renewable energy policy selection with unknown information, Renew. Sustain. Energy Rev., 68, 774-787 (2017)

16 M. Martínez-García, A. Valls, A. Moreno, and A. Aldea, A semantic multi-criteria approach to evaluate different types of energy generation technologies, Environ. Model. Softw., 110, 129-138 (2018)

17 E. Turban, J. E. Aronson, and T.-P. Llang, Decision Support Systems and Intelligent Systems, 7th Editio. New Delhi, India (2007)

18 A. Mardani, A. Jusoh, K. M. D. Nor, Z. Khalifah, N. Zakwan, and A. Valipour, Multiple criteria decision-making techniques and their applications - A review of the literature from 2000 to 2014, Econ. Res. Istraz. , 28, 516-571 (2015)

19 Wahyunto et al., Petunjuk Teknis Pedoman Penilaian Kesesuaian Lahan untuk Komoditas Pertanian Strategis Tingkat Semi Detail Skala 1: 50.000, April 2016. Bogor, Indonesia (2016)

20 M. Rogers, M. Bruen, and L.-Y. Maystre, ELECTRE and Decision Support: Methods and Applications in Engineering and Infrastructure Investment. New York (2000) 